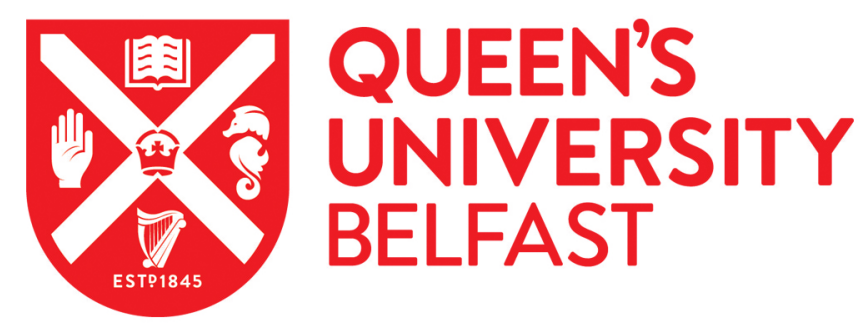

\title{
In situ forming phase-inversion implants for sustained ocular delivery of triamcinolone acetonide
}

\author{
Sheshala, R., Chew Hong, G., Pui Yee, W., Srikanth Meka, V., \& Singh Thakur, R. R. (2018). In situ forming \\ phase-inversion implants for sustained ocular delivery of triamcinolone acetonide. Drug Delivery and \\ Translational Research, 1-9. https://doi.org/10.1007/s13346-018-0491-y
}

Published in:

Drug Delivery and Translational Research

Document Version:

Peer reviewed version

Queen's University Belfast - Research Portal:

Link to publication record in Queen's University Belfast Research Portal

Publisher rights

(c) Controlled Release Society 2018.

This work is made available online in accordance with the publisher's policies. Please refer to any applicable terms of use of the publisher.

\section{General rights}

Copyright for the publications made accessible via the Queen's University Belfast Research Portal is retained by the author(s) and / or other copyright owners and it is a condition of accessing these publications that users recognise and abide by the legal requirements associated with these rights.

Take down policy

The Research Portal is Queen's institutional repository that provides access to Queen's research output. Every effort has been made to ensure that content in the Research Portal does not infringe any person's rights, or applicable UK laws. If you discover content in the Research Portal that you believe breaches copyright or violates any law, please contact openaccess@qub.ac.uk. 
In situ forming phase-inversion implants for sustained ocular delivery of triamcinolone acetonide

Ravi Sheshala*1,2, Gan Chew Hong ${ }^{1}$, Wong Pui Yee ${ }^{1}$, Venkata Srikanth Meka ${ }^{1}$, Thakur Raghu Raj Singh*3

${ }^{1}$ School of Pharmacy, International Medical University, Bukit Jalil, 57000 Kuala Lumpur, Malaysia.

${ }^{2}$ Department of Pharmaceutics, Faculty of Pharmacy, Universiti Teknologi MARA Selangor, Puncak Alam Campus, 42300, Puncak Alam, Kuala Selangor, Malaysia

${ }^{3}$ School of Pharmacy, McClay Research Centre, Queens University Belfast, Belfast, Northern Ireland, 97 Lisburn Road, BT9 7BL, United Kingdom

\section{*Corresponding authors}

\section{Ravi Sheshala}

E-mail: ravisheshala@uitm.edu.my

Tel: +6-03-32584836

ORCID: 0000-0001-5255-3238

\section{Thakur Raghu Raj Singh}

E-mail: r.thakur@qub.ac.uk

Tel: +44 (0) 2890975814

ORCID: 0000-0001-7582-2082

\section{Acknowledgements}

The authors would like to thank International Medical University, Kuala Lumpur, Malaysia for providing research grant (BPharm B0110_Res012013) and Queen's University Belfast, Belfast, UK for providing the facilities to carry out this research work. 


\begin{abstract}
The objectives of this study were to develop biodegradable polylactic-co-glycolic acid (PLGA) based injectable phase inversion in situ forming system for sustained delivery of triamcinolone acetonide (TA) and to conduct physicochemical characterization including in vitro drug release of the prepared formulations. TA (at $0.5 \%, 1 \%$ and 2.5\% w/w loading) was dissolved in N-methyl-2-pyrrolidone (NMP) solvent and then incorporated 30\% w/w PLGA (50/50 and 75/25) polymer to prepare homogenous injectable solution. The formulations were evaluated for rheological behaviour using rheometer; syringeability by Texture Analyser; water uptake and rate of implant formation by optical coherence tomography (OCT) microscope. Phase inversion in situ forming formulations were injected into PBS pH 7.3 to form an implant and release samples were collected and analysed for drug content using a HPLC method. All formulations exhibited good syringeability and rheological properties (viscosity: 0.193.06 Pa.s) by showing shear thinning behaviour which enable them to remain as free flowing solution for ease administration. The results from OCT microscope demonstrated that thickness of the implants were increased with the increase in time and the rate of implant formation indicated the fast phase inversion. The drug release from implants was sustained over a period of 42 days. The research findings demonstrated that PLGA/NMP-based phase inversion in situ forming implants can improve compliance in patient's suffering from ocular diseases by sustaining the drug release for a prolonged period of time and thereby reducing the frequency of ocular injections.
\end{abstract}

Keywords In situ implant, ocular, ophthalmic, triamcinolone acetonide, PLGA, phase inversion 


\section{Introduction}

Posterior segment eye diseases often contributes to the most prevalent causes of visual impairment and blindness worldwide. The World Health Organization estimates that globally about 285 million people are visually impaired; 39 million are blind and 246 million have low vision [1]. Majority of eye diseases that causes visual impairment typically originates in the posterior segment of the eye such as age-related macular degeneration (AMD), diabetic retinopathy (DR), diabetic macular edema (DME), uveitis and retinitis [2]. Treating these diseases is challenging owing to the extremely delicate nature of the tissues concerned and their relative inaccessibility. Regardless of aforementioned causes, ineffectiveness of conventional treatment also represents enormous challenges to the researchers owing to the poor absorption and therapeutic response of drug molecules associated with rapid precorneal elimination and multiple protective barriers of the eye. As a result, frequent drug administration is required causing low patient's compliance [3]. In order to overcome these shortcomings, intensive efforts have been devoted to the fabrication of new injectable drug delivery system aiming to achieve effective drug delivery to the targeted site of action, sustain the drug release and enhance bioavailability.

Intravitreal delivery (IVD), a direct injection of therapeutic agents into the eyes, is a standard practice to treat posterior segment diseases. However, due to the chronic nature of the above conditions, and the short acting nature of available therapies, patients require frequent dosing (e.g., every 4-6 weeks) over many years. Furthermore, this route is also associated with severe side effects, such as high therapeutic dosage-induced ocular toxicity, pain and discomfort, vitreous haemorrhage and cataract development $[3,4]$.

Currently, development of in situ forming implant (ISFI) has gained tremendous popularity as it avoids the need for frequent injections in the eye or surgical implantation. In contrast, ISFIs are injected as low viscous solution that transform to a solid depot or implant at the site of action which in turn controls drug delivery [6]. This stimulation of sol-to-gel transformation requires appropriate amount of triggers depending on the mechanisms i.e. solidifying organogels, cross-linking systems and phase separation/inversion system [4]. The phenomenon of phase separation from a solution occurs due to the changes in their environmental temperature, $\mathrm{pH}$ or by solvent exchange. In the present research, exclusively focused on the phase inversion-based ISFI by solvent exchange as they are easy to manufacture in few simple steps and does not require any trigger to stimulate the transformation and also they represent an excellent strategy for ocular controlled drug release applications. The phase inversion-based ISFI concept was first introduced by Dunn et al. (1999) [7] comprising a water insoluble polymer, dissolved with water miscible and physiologically biocompatible organic solvents incorporated 
with a required drug [6]. Upon injection into aqueous medium such as vitreous humour of the eye, phase separation occurs with an influx of water fluid to the solid depot and outflow of organic solvents to surrounding tissue causing precipitation of polymer followed by entrapment of drug molecules within the matrix of polymer as it solidifies. Finally, the drug is being released slowly by diffusion and/or as the implants biodegrades (Fig. 1) [8, 9].

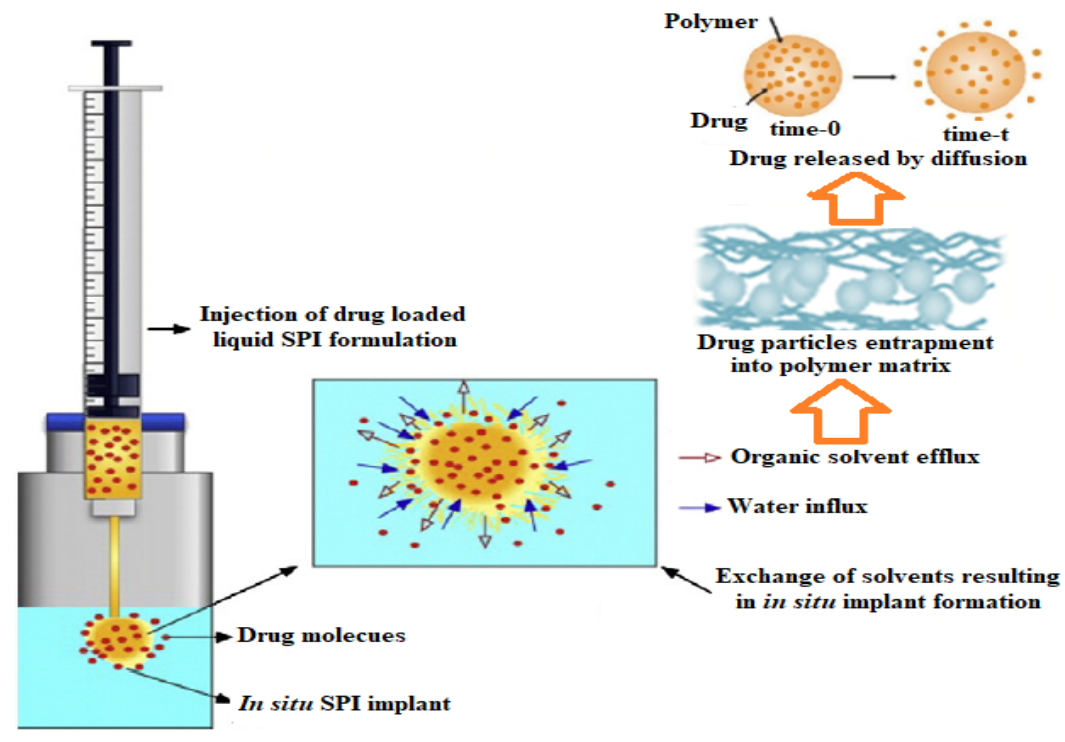

Fig. 1 Schematic representations of ISFI formation by solvent exchange technique and drug delivery. (Adopted and modified from Thakur et al. 2014) [5]

The unique characteristics of polymer incorporated into the ISFI plays a vital role in the rate of drug release and magnitude of phase inversion dynamic. The key selection of polymers should possess physical and chemical stability, biocompatibility and water immiscibility that allow polymer precipitation and implant formation [9, 10]. Polylactic-co-glycolic acid (PLGA) has been among the most promising and attractive polymeric alternative which is used to facilitate the drug delivery system. This has been sparked by various advantages shown by the properties of the polymer such that it is physiologically biocompatible, biodegradable, and approved by USFDA $[4,6,11]$. Depending on the copolymer ratios and molecular weight, PLGA offers a wide range of degradation characteristics and burst release effects. Hence, PLGA 50/50 and PLGA 75/25 were selected to investigate the sustained delivery of triamcinolone acetonide (TA), which is used in the treatment of chronic ocular diseases such as AMD, DME and DR. The aim of the present research is to formulate and characterize PLGA based phase inversion ISFI consisting of TA. This technology could potentially enhance patient's compliance by reducing the frequency of drug administration. 


\section{Materials and Methods}

\section{Materials}

Poly-lactic-co-glycolic acid (PLGA) (50/50 and 75/25) was purchased from Purac Biomaterials, Netherlands. Nmethyl-2-pyrrolidone (NMP) was purchased from Sigma Aldrich, England. Triamcinolone acetonide (TA) was obtained from BUFA, Netherlands. Phosphate buffer solution (PBS) was obtained from Sigma-Aldrich Company, England. Acetonitrile of HPLC grade was purchased from Fischer Scientific, United Kingdom.

\section{Preparation of Biodegradable Phase-Inversion Based ISFI}

The composition of prepared formulations is shown in Table 1. Briefly, the required amount of TA were accurately weighed and dissolved in NMP. Then, 30\% w/w of PLGA 50/50 or PLGA 75/25 was incorporated into the solution and stirred overnight at $200 \mathrm{rpm}$ to obtain homogenous and clear injectable solution. These solutions were transformed into a solid implant when injected into phosphate buffer solution (PBS), pH 7.3.

Table 1 Composition of ISFI formulations containing different drug concentrations.

\begin{tabular}{ccccc}
\hline Formulation & $\begin{array}{c}\text { TA } \\
(\% \text { /w })\end{array}$ & $\begin{array}{c}\text { PLGA 50/50 } \\
(\% \mathbf{\%} / \mathbf{w})\end{array}$ & $\begin{array}{c}\text { PLGA 75/25 } \\
(\% \mathbf{\%} / \mathbf{w})\end{array}$ & $\begin{array}{c}\text { NMP } \\
(\% \mathbf{\%} / \mathbf{w})\end{array}$ \\
\hline F1-0\% TA & 0 & 30 & - & 70.0 \\
F1-0.5\% TA & 0.5 & 30 & - & 69.5 \\
F1-1.0\% TA & 1.0 & 30 & - & 69.0 \\
F1-2.5\% TA & 2.5 & 30 & - & 67.5 \\
\hline F2-0\% TA & 0 & - & 30 & 70.0 \\
F2-0.5\% TA & 0.5 & - & 30 & 69.5 \\
F2-1.0\% TA & 1.0 & - & 30 & 69.0 \\
F2-2.5\% TA & 2.5 & - & 30 & 67.5 \\
\hline
\end{tabular}

\section{HPLC method for TA analysis}

A stock solution of TA $(1 \mathrm{mg} / \mathrm{ml})$ was prepared by dissolving the drug in PBS, $\mathrm{pH} 7.3$. It was then diluted to a series of drug concentrations ranging from 1 to $250 \mu \mathrm{g} / \mathrm{ml}$. These solutions were analysed using Agilent 1260 Infinity Quaternary System HPLC (Agilent Technologies Ltd., Stockport, UK) connected to UV/Visible spectrophotometer which was set at $236 \mathrm{~nm}$. A reverse phase Agilent Zorbax C18 column $(150 \times 4.6 \mathrm{~mm}$ i.d., 5 $\mu \mathrm{m}$ particle size) with Agilent Zorbax guard column held at $25^{\circ} \mathrm{C}$ (Agilent Technologies Ltd., Stockport, UK) was used for the chromatographic separation. The mobile phase consisted of a mixture of $60 \%$ water and $40 \%$ acetonitrile and was delivered at a flow rate of $0.8 \mathrm{ml} / \mathrm{min}$. The injection volume was $20 \mu \mathrm{l}$. The calibration curve 
equation was derived from the areas of the TA absorbance peak plotted against respective drug concentration. This HPLC method was used to determine the $\%$ of drug release from the prepared ISFI formulations.

\section{Rheological characterisation of ISFI}

\section{Viscosity measurements and behaviour}

The rheological behaviour of all the formulations was investigated using an AR 200 rheometer (T.A instruments, Surrey, UK) in flow mode at $21 \pm 0.1{ }^{\circ} \mathrm{C}$, using $20 \mathrm{~mm}$ steel plate $[6,12]$. A gap of $500 \mu \mathrm{m}$ along with a constant force of $5.0 \mathrm{~N}$ were set. The formulations were exposed to a continuous shear rate ranging from $0-50 / \mathrm{s}$. Viscosity was determined using power law set by the program. The measurements were carried out in triplicate.

\section{Dynamic viscoelastic measurement}

Stress sweep test was performed under oscillatory mode by applying oscillatory stress from 0-50 $\mathrm{Pa}$ at constant frequency of $0.1 \mathrm{~Hz}$ in order to determine the stability of formulations-linear viscoelasticity region (LVER). Then, a frequency sweep test was performed by exerting a constant sheer stress obtained from LVER (5 Pa) with increasing frequency from 0.1 to $1 \mathrm{~Hz}[11-13]$.

\section{Syringeability Test}

A Texture Analyser (TA-TX2, Stable Micro Systems, Surrey, UK), set in compression mode, was used to determine the maximum forces and work (syringeability) required to inject the polymeric formulations at $21^{\circ} \mathrm{C}$. The set-up of Texture Analyzer is shown in Fig. 2. The needles of $27 \mathrm{G}$ and $29 \mathrm{G}$ with two sample sizes of $0.1 \mathrm{ml}$ and $0.2 \mathrm{ml}$ were used. A downward force of $0.05 \mathrm{~N}$ was applied with plunger displacement of $60 \mathrm{~mm}(27 \mathrm{G})$ and $120 \mathrm{~mm}(29 \mathrm{G})$. Work of syringeability was determined by the area under the curve derived from the resultant force-distance plot [14]. 


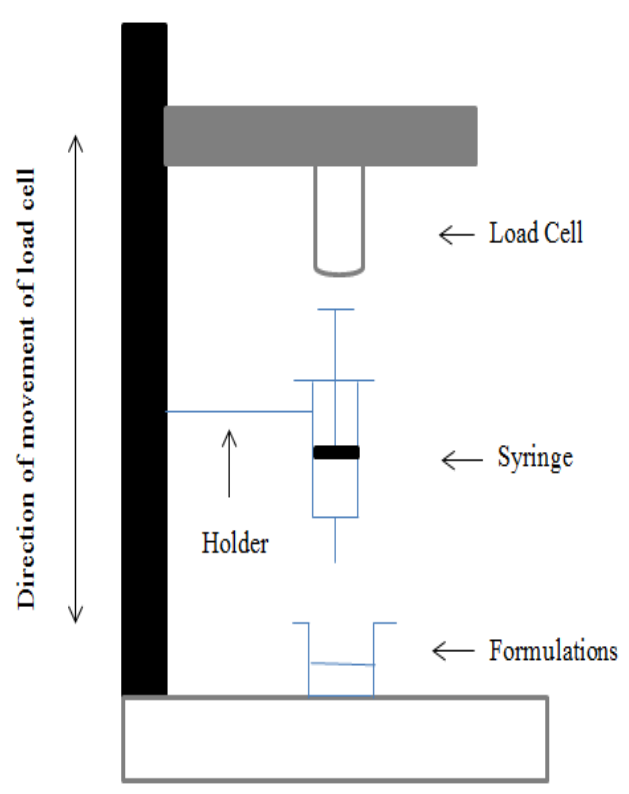

Fig. 2 Schematic representation of Texture Analyzer set-up for syringeability test.

\section{Visualization of implants formation}

A Vivosight ${ }^{\circledR}$ optical coherence tomography (OCT) microscope (Michelson Diagnostics, Massachusetts, USA) was used to examine the behavior (water uptake) and rate of implant formation of blank formulations (F1-0\% TA and F2-0\% TA) at regular intervals of $1,4,7$ and $24 \mathrm{~h}$. The images captured were analysed using Image J software to measure the thickness of outer shell of the implants formed during solidification process [6, 14].

\section{In vitro drug release studies}

Prior to injection, the formulations were centrifuged at $3000 \mathrm{rpm}$ for $1 \mathrm{~min}$ to ensure the solutions were free from bubbles. About $0.17 \mathrm{ml}$ of formulation was gradually injected into glass vials containing $5 \mathrm{ml}$ PBS, pH 7.3 and solid spherical implant was formed within a few seconds. Then, the vials were kept in an incubator at $37{ }^{\circ} \mathrm{C}$ and $60 \mathrm{rpm}$. About $1 \mathrm{ml}$ of sample was withdrawn at predetermined time intervals $(1,7,10,14,21,28,35$ and 42 days) and analysed the samples to determine the \% of drug release using HPLC. The remaining medium was removed and replaced with fresh medium [15]. The data obtained from in vitro drug release study was fitted into mathematical modelling equations (Table 2) to determine the release pattern and release mechanism of the drug from the prepared formulations. The best fit model of release pattern was considered with highest regression value $\left(\mathrm{r}^{2}\right)$ of zero and first order. The regression values of Higuchi model which indicate diffusion mechanism and Hixon-crowell model which indicate erosion mechanism were compared to identify the release mechanism. The release mechanism is further confirmed by the slop value (n) of Korsemeyer-peppas model. 
Table 2 Mathematical modelling equations used to determine release rate and mechanism of TA from ISFI.

\begin{tabular}{lc}
\hline \multicolumn{1}{c}{ Mathematical model } & Equation \\
\hline Zero-order & $Q_{t}=Q_{0}+k_{0} \mathrm{t}$ \\
First-order & $\log Q t=\log Q_{0}-K t / 2.303$ \\
Higuchi & $Q_{t}=k_{H} t^{1 / 2}$ \\
Hixson-Crowell & $W_{0}{ }^{1 / 3}-W_{t}{ }^{1 / 3}=K_{s} t$ \\
Korsemeyer-Peppas & $\mathrm{Q}_{\mathrm{t}} / \mathrm{Q}_{\infty}=K_{k} t^{n}$ \\
\hline $\begin{array}{l}\mathrm{Q}_{\mathrm{t}}=\text { Amount of drug released in time ' } \mathrm{t} \text { '; } \mathrm{Q}_{0}=\text { Initial amount of drug in } \\
\text { the dosage form; } \mathrm{Q}_{\mathrm{t}} / \mathrm{Q}_{\infty}=\text { fraction of drug released at time " } \mathrm{t} \text { "; } \mathrm{k}_{0}, \mathrm{~K}, \mathrm{k}_{\mathrm{H}}, \\
\mathrm{K}_{\mathrm{s}} \text { and } \mathrm{K}_{\mathrm{k}}=\text { Release rate constants; } \mathrm{n}=\text { release exponent (indicative of } \\
\text { release mechanism) }\end{array}$ \\
\hline
\end{tabular}

\section{Statistical analysis}

The results are reported as mean \pm standard deviation (S.D.). The viscosity results of prepared formulations were treated statistically using one-way analysis of variance (ANOVA). When there was a statistically significant difference, a post hoc Tukey's honestly significant difference (HSD) test was performed. A statistical significant difference was considered at $\mathrm{p}<0.05$.

\section{Results}

\section{Calibration curve of TA}

The calibration curve of TA was showed linearity in the concentration range of $1-250 \mu \mathrm{g} / \mathrm{ml}$ with regression value of 0.999. The chromatogram of TA was shown in Fig. 3 and the retention time of TA was 10.42 min.

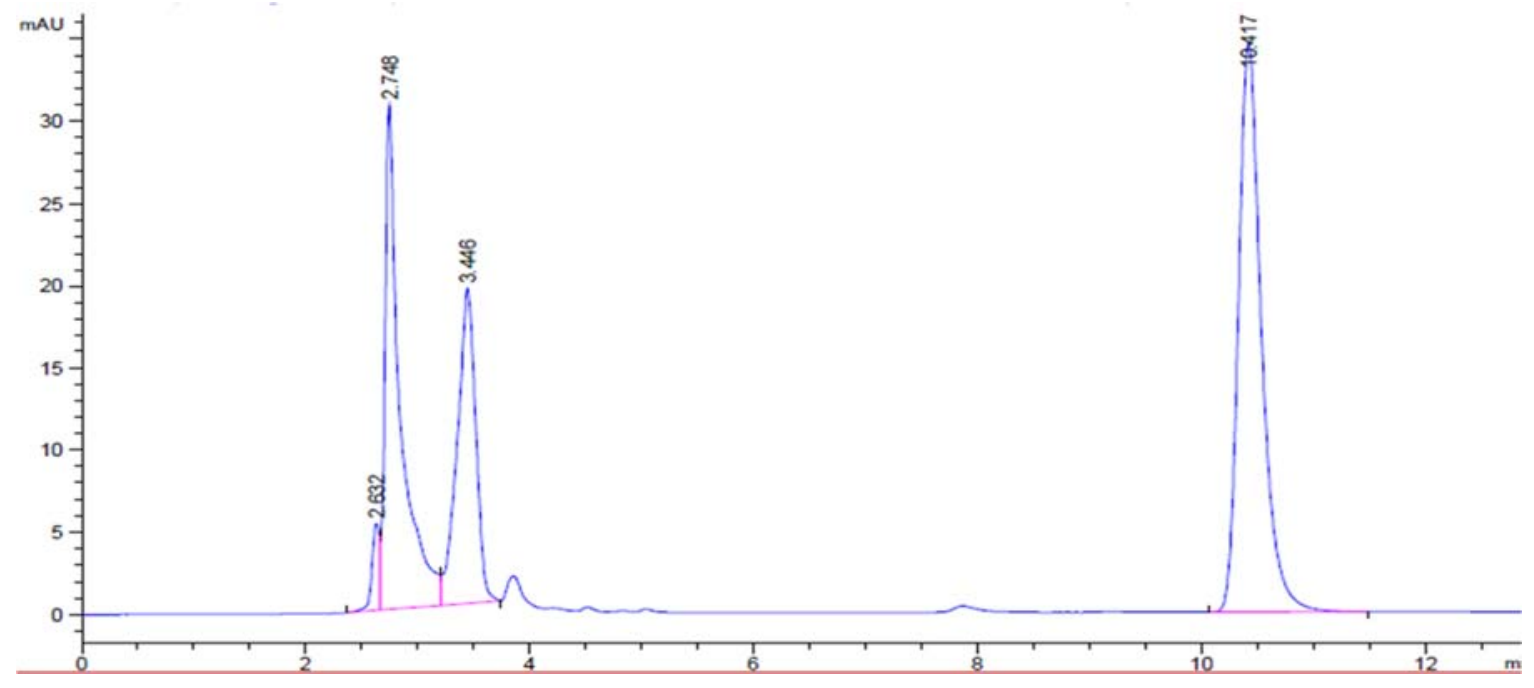

Fig. 3 HPLC chromatogram of TA at $236 \mathrm{~nm}$. 


\section{Flow properties of ISFI formulations by rheological measurement}

Table 3 shows the flow dynamic properties of PLGA/NMP system. As shear rate increases from 0-50/s, viscosity of formulations was decreased. All polymeric solutions exhibited pseudoplastic (shear thinning) behaviour with a rate index of below 1. The viscosity of the formulations was increased from 0.29-0.83 Pa.s with the increase in drug concentrations from $0-2.5 \%$ for the formulations prepared using PLGA 50/50. However, there was no statistically significant difference ( $\mathrm{p}>0.05)$ in the viscosity results of $\mathrm{F} 1-0 \%$ TA to F1-0.5\% TA and F3-1\% TA. The viscosity of blank formulation prepared with PLGA 75/25 was higher (3.06 Pa.s) compared to the formulations loaded with TA at concentrations of $0.5-2.5 \%(0.19-0.28$ Pa.s $)$ and found to be statistically significant difference among all the formulations ( $\mathrm{p}<0.05$ ). Higher viscosity with PLGA $75 / 25$ is due to the copolymer type i.e. composition of lactide(LA)/glycolide(GA) ratio which breaks with the incorporation of drug molecule that reduces the polymer-polymer intersegmental interactions thereby reducing the viscosity in NMP whereas PLGA 50/50 which has less amount of LA content compared to PLGA 75/25 which shows less effect with increasing TA content.

Table 3 Results of viscosity and rate index of different formulations.

\begin{tabular}{ccc}
\hline Formulation & $\begin{array}{c}\text { Viscosity (Pa.s) } \\
(\text { Mean } \pm \text { SD, } \mathbf{N}=\mathbf{3})\end{array}$ & Rate Index \\
\hline F1-0\% TA & $0.29 \pm 0.02$ & 0.916 \\
F1-0.5\% TA & $0.46 \pm 0.04$ & 0.989 \\
F1-1.0\% TA & $0.54 \pm 0.05$ & 0.904 \\
F1-2.5\% TA & $0.83 \pm 0.06$ & 0.835 \\
F2-0\% TA & $3.06 \pm 0.22$ & 0.466 \\
F2-0.5\% TA & $0.19 \pm 0.04$ & 0.975 \\
F2-1.0\% TA & $0.27 \pm 0.04$ & 0.960 \\
F2-2.5\% TA & $0.28 \pm 0.05$ & 0.951 \\
\hline
\end{tabular}

\section{Viscoelastic measurements}

All the formulations have demonstrated the same trend where they experienced fluid-like behaviour at low frequencies $\left(G^{\prime}>G^{\prime}\right)$ and gel-like behaviour at high frequencies $\left(G^{\prime}>G^{\prime}\right)$. Transition point where $G^{\prime}=G^{\prime}$, ranging 
between $0.3-0.8 \mathrm{~Hz}$ were observed as shown in Table 4 . This indicates the tendency of the formulations to undergo sol-to-gel transformation at the particular cross-over frequency and continued to behave as a gel $[14,16]$.

Table 4 Results of cross over frequency of different formulations.

\begin{tabular}{ccccc}
\hline Formulation & $\begin{array}{c}\text { Frequency } \\
(\mathbf{H z})\end{array}$ & $\begin{array}{c}\text { Elastic modulus } \\
\text { G' }(\mathbf{P a})\end{array}$ & $\begin{array}{c}\text { Viscous modulus } \\
\text { G\% }(\mathbf{P a})\end{array}$ & $\begin{array}{c}\text { tan } \\
\text { (delta) }\end{array}$ \\
\hline F1-0\% TA & 0.5042 & 0.7378 & 0.7608 & 1.031 \\
F1-0.5\% TA & 0.8162 & 1.820 & 1.871 & 1.028 \\
F1-1.0\% TA & 0.8715 & 2.091 & 2.134 & 1.020 \\
F1-2.5\% TA & 0.8715 & 2.118 & 2.125 & 1.003 \\
F2-0\% TA & 0.8347 & 2.304 & 2.282 & 0.990 \\
F2-0.5\% TA & 0.3756 & 0.4174 & 0.4224 & 1.012 \\
F2-1.0\% TA & 0.4859 & 0.6011 & 0.5944 & 0.989 \\
F2-2.5\% TA & 0.4306 & 0.5232 & 0.5244 & 1.002 \\
\hline
\end{tabular}

\section{Syringeability test}

The syringeability and maximum force required to expel the formulations with different needle size are shown in Table 5. Work required to expel the formulations from $27 \mathrm{G}$ and $29 \mathrm{G}$ needle were increased with increasing sample volume from $0.1 \mathrm{ml}$ to $0.2 \mathrm{ml}$. This is due to the higher resistance force associated with increasing plunger displacement. In addition, the maximum force required to expel both sample solutions increased with decreasing the needle inner diameter from $0.210 \mathrm{~mm}(27 \mathrm{G})$ to $0.184 \mathrm{~mm}(29 \mathrm{G})$.

\section{Visualisation of implant formation}

The OCT images are shown in Fig. 4. The outer shell thickness of implants (F1-0\% TA and F2-0\% TA) were increased with the time increment from 1 to 24 hours. This indicates the occurrence of fast phase inversion with rapid water uptake due to the strong hydrophilic nature of NMP, which causes the expansion of implant (Table 6) [14]. 
Table 5 Results of work of syringeability and maximum forces required to expel different volumes of formulations with different needle size.

\begin{tabular}{|c|c|c|c|c|}
\hline Formulations & $\begin{array}{l}\text { Syringe } \\
\text { (gauge) }\end{array}$ & $\begin{array}{c}\text { Volume } \\
\text { (ml) }\end{array}$ & $\begin{array}{c}\text { Syringeability } \\
(\text { Mean } \pm \text { SD, } N=3)\end{array}$ & $\begin{array}{c}\text { Maximum Force }(\mathbf{N}) \\
(\operatorname{Mean} \pm \mathrm{SD}, \mathbf{N}=3)\end{array}$ \\
\hline \multirow{4}{*}{ F1-0\% TA } & \multirow[b]{2}{*}{27} & 0.1 & $49.01 \pm 1.26$ & $11.17 \pm 0.29$ \\
\hline & & 0.2 & $140.99 \pm 6.51$ & $14.65 \pm 0.79$ \\
\hline & \multirow[b]{2}{*}{29} & 0.1 & $104.87 \pm 0.20$ & $31.08 \pm 0.77$ \\
\hline & & 0.2 & $246.74 \pm 3.73$ & $41.34 \pm 0.99$ \\
\hline \multirow{4}{*}{ F2-0\% TA } & \multirow{2}{*}{27} & 0.1 & $34.99 \pm 3.44$ & $7.22 \pm 0.97$ \\
\hline & & 0.2 & $75.48 \pm 13.72$ & $11.16 \pm 0.05$ \\
\hline & \multirow{2}{*}{29} & 0.1 & $80.14 \pm 2.82$ & $21.15 \pm 0.74$ \\
\hline & & 0.2 & $200.46 \pm 3.02$ & $25.80 \pm 0.45$ \\
\hline
\end{tabular}

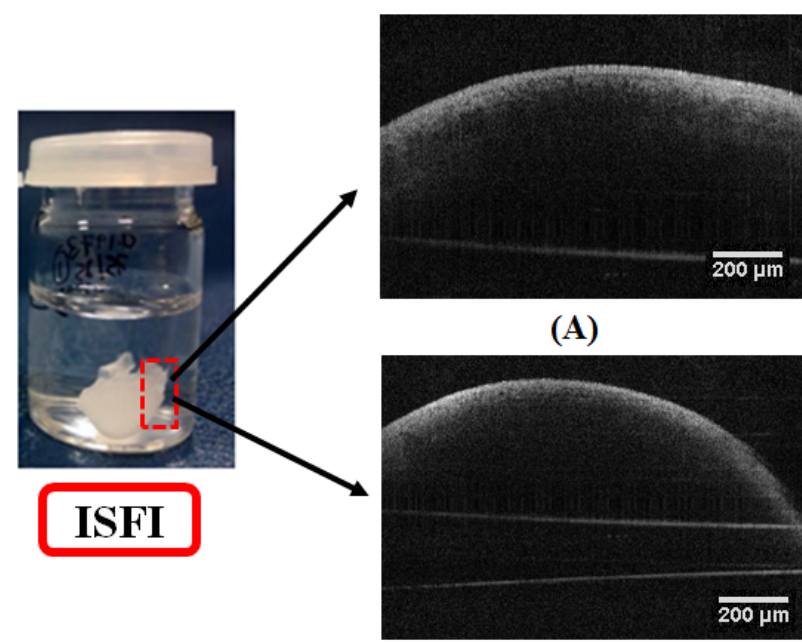

(C)

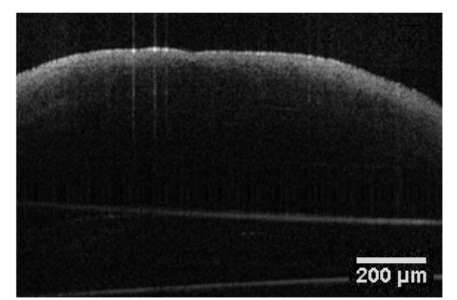

(B)

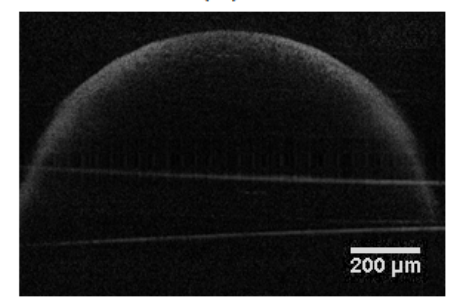

(D)

Fig. 4 OCT images (scale bar $200 \mu \mathrm{m}$ ): (A) and (B) Thickness of PLGA 50/50 implants at $1 \mathrm{~h}$ and $24 \mathrm{~h}$; (C) and (D) Thickness of PLGA 75/25 implants at $1 \mathrm{~h}$ and $24 \mathrm{~h}$. The thickness of implants were increased with increase in time from $1 \mathrm{~h}$ to $24 \mathrm{~h}$.

Table 6 Thickness of outer shell of implants at different time intervals.

\begin{tabular}{c|cc}
\hline Formulations & Time (h) & $\begin{array}{c}\text { Thickness }(\boldsymbol{\mu m}) \\
\text { Mean } \pm \text { SD, N=3 }\end{array}$ \\
\hline & $\mathbf{1}$ & $358.4 \pm 24.61$ \\
F1-0\% TA & $\mathbf{4}$ & $419.5 \pm 16.15$ \\
& $\mathbf{7}$ & $436.8 \pm 14.55$ \\
& $\mathbf{2 4}$ & $470.4 \pm 27.54$ \\
\hline & $\mathbf{1}$ & $286.5 \pm 38.41$ \\
F2-0\% TA & $\mathbf{4}$ & $305.1 \pm 70.14$ \\
& $\mathbf{7}$ & $334.5 \pm 39.00$ \\
& $\mathbf{2 4}$ & $368.7 \pm 84.25$ \\
\hline
\end{tabular}




\section{In vitro drug release studies}

In vitro drug release results are shown in and Fig. 5. The implants containing $0.5 \%$ TA of F1 and F2 exhibited a biphasic release pattern where there was a noticeable initial burst release of $14.7 \%$ and $28.91 \%$ respectively on the first day followed by a constant and sustained drug release of $60.24 \%$ and $63.15 \%$, respectively in a period of 42 days. In contrast, implants with $1 \%$ TA of F1 and F2 were released about $38.41 \%$ and $33.06 \%$, respectively whereas implants with $2.5 \%$ TA of F1 and F2 were released $17.79 \%$ and $18.58 \%$ respectively over a period of 42 days. These formulations demonstrated a consistent and uniform drug release without any initial burst release. The implant images captured at 1, 28 and 42 days of in vitro drug release studies are shown in Fig. 6. The images depicted that the implants were degraded over a time from 1 to 42 days which aid to the confirmation of biodegradation of the formed implant. Hence, no surgery is required as it results in natural loss of implant material after injection of implants. The drug release data was fitted into mathematical release kinetic models and the results demonstrated higher $\mathrm{r}^{2}$ value for first order and release exponent (n) value was greater than 0.6 for all the formulations (Table 7).

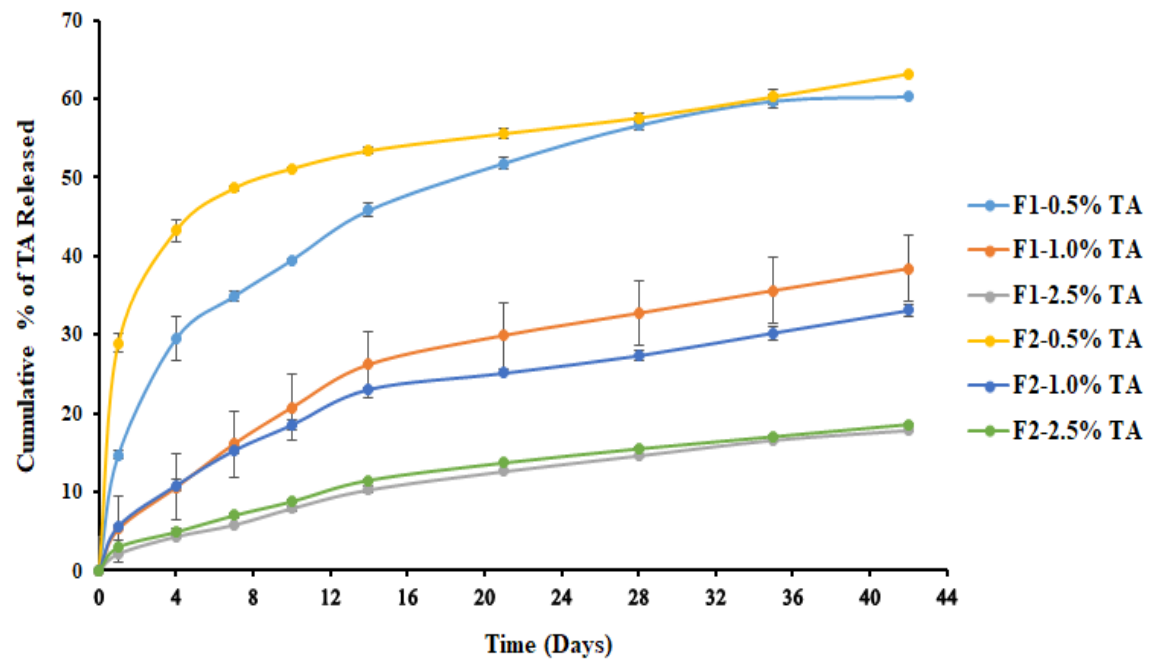

Fig. 5 Cumulative \% of TA released from of ISFI containing different drug concentrations. 


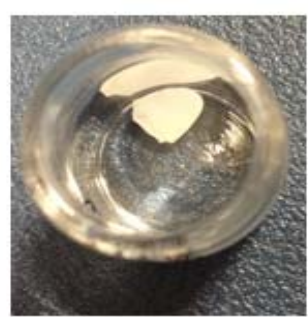

(A)

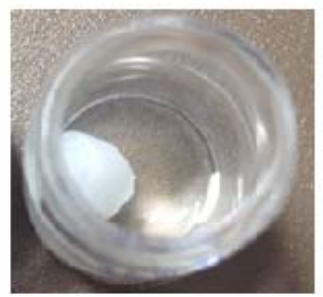

(D)

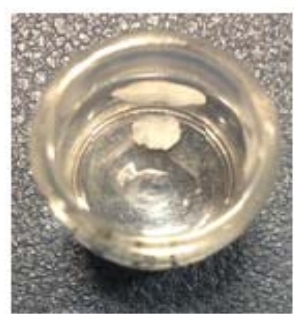

(B)

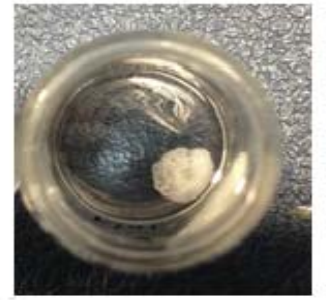

(E)

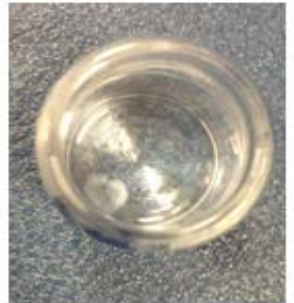

(C)

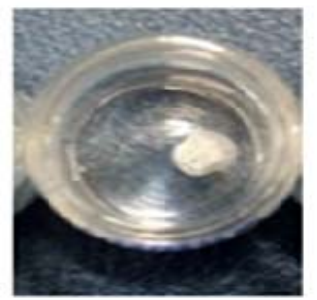

(F)

Fig. 6 (A), (B) and (C): PLGA 50/50 implants on the days of 1, 28 and 42; (D), (E) and (F): PLGA 75/25 implants on the days of 1,28 and 42 .

Table 7 Release kinetics results of TA loaded ISFI formulations.

\begin{tabular}{lcccccc}
\hline Formulation & $\begin{array}{c}\text { Zero order } \\
\left(\mathbf{R}^{\mathbf{2}}\right)\end{array}$ & $\begin{array}{c}\text { First order } \\
\left(\mathbf{R}^{\mathbf{2}}\right)\end{array}$ & $\begin{array}{c}\text { Higuchi } \\
\mathbf{( \mathbf { R } ^ { 2 } )}\end{array}$ & $\begin{array}{c}\text { Hixon- } \\
\text { Crowell }\left(\mathbf{R}^{\mathbf{2}}\right)\end{array}$ & \multicolumn{2}{c}{ Korsemeyer-Peppas } \\
\hline F1-0.5\% TA & $0.892 \pm 0.013$ & $0.932 \pm 0.003$ & $0.974 \pm 0.004$ & $0.910 \pm 0.012$ & $0.985 \pm 0.012$ & $0.640 \pm 0.112$ \\
F1-1.0\% TA & $0.913 \pm 0.028$ & $0.936 \pm 0.026$ & $0.984 \pm 0.003$ & $0.929 \pm 0.027$ & $0.998 \pm 0.002$ & $0.750 \pm 0.005$ \\
F1-2.5\% TA & $0.974 \pm 0.002$ & $0.979 \pm 0.005$ & $0.989 \pm 0.009$ & $0.977 \pm 0.003$ & $0.966 \pm 0.023$ & $0.655 \pm 0.052$ \\
F2-0.5\% TA & $0.872 \pm 0.077$ & $0.885 \pm 0.069$ & $0.840 \pm 0.060$ & $0.815 \pm 0.070$ & $0.985 \pm 0.010$ & $0.645 \pm 0.044$ \\
F2-1.0\% TA & $0.885 \pm 0.070$ & $0.904 \pm 0.008$ & $0.973 \pm 0.005$ & $0.898 \pm 0.008$ & $0.998 \pm 0.002$ & $0.728 \pm 0.076$ \\
F2-2.5\% TA & $0.958 \pm 0.017$ & $0.965 \pm 0.015$ & $0.986 \pm 0.005$ & $0.963 \pm 0.016$ & $0.994 \pm 0.006$ & $0.674 \pm 0.059$ \\
\hline
\end{tabular}

\section{Discussion}

ISFI is one of the new and smart injectable drug delivery systems where the drug can be injected into the localised tissue as a liquid material in a minimally invasive manner which solidifies at the site of injection providing sustained drug delivery. Besides, the manufacturing steps are also simple and easy to scale-up, one of the simplest approaches to fabricate ISFI is phase inversion. The simple mechanism involved in sustaining the drug release through the phase inversion technique is the influx of non-solvent (water/body fluids) and efflux of water miscible organic solvent organic solvent (NMP) from the dose administered causes to precipitate the water immiscible polymer (PLGA) and entraps the drug in the matrix [5]. 
Triamcinolone acetonide, a corticosteroid having therapeutic potentials to treat the posterior segment of the ocular diseases i.e. intraocular edematous, DME, proliferative DR, retinal vein occlusions, uveitis including sympathetic ophthalmia, and exudative AMD. Currently, TA is administered as intravitreal injections which is having aforementioned potential side effects due to the frequency of the dose administration. Hence, in the present research work aimed to develop and characterize TA loaded ISFI using phase inversion technique.

The rheological changes have made injection easy as the solutions remained free-flowing at room temperature and subsequently transformed to gel phase once they are injected into the eye $[6,14]$. Both the volume of injection and gauge of the needle influences the syringeability and force required to administer the dose into the ocular region. The syringeability test results demonstrated that the implants could be administered through a small gauge needle. Hence, $27 \mathrm{G}$ needle was considered to be a better choice than $29 \mathrm{G}$ as it requires less force to inject the injection, which consequently enables easy administration without rendering injection difficulty or painful.

The in vitro drug release results depicted that the relatively high initial burst release from formulations containing $0.5 \%$ TA of F1 and F2 was due to the fast transition of sol-to-gel formation which was driven by the rapid dissipation of highly water miscible organic solvent NMP into aqueous environment. Therefore, TA presented on the surface diffused out rapidly through large pores and water accessible channels which were created during fast phase separation [6].

However, uncommon phenomenon was observed where the rate of drug release decreases as drug concentration increases without any burst release. This could be explained by the hydrophobic nature of TA where it experienced more intense hydrophobic drug-polymer interaction. As a result, the drug molecules retained at the polymer matrix as it solidifies resulting in less diffusion of drug molecules. In addition, increased viscosity of the formulations together with the hydrophobicity of the matrix also contributed to this event where it retards the water uptake system and slowing phase inversion process. All these factors were assumed to exert a great impact to the rate of drug release, causing distinctive total releases of drug between the three formulations. Nevertheless, this is a good scenario in the aspects of therapeutic and economic view as it is able to prolong the effective lifespan of the implant. Furthermore, the less susceptibility to burst release is also beneficial where it minimize the potential local and systemic toxicity especially when dealing with narrow therapeutic index drugs. 
At day 1 of in vitro release study, the implants showed a smooth surface, and as the time progresses the implants appeared to be with porous surface and become smaller in size by day 42 (Fig. 6). The degradation of implant mass was due to the hydrolytic process of the matrix and the drug, resulting in the release of watersoluble PLGA degradation products (lactic and glycolic acid) which are eliminated from the body through Krebs cycle $[4,5]$. Therefore, the entire polymer matrix was hydrolyzed leading to a homogenous degradation products formation and later bulk erosion [3].

All formulations exhibited first-order release pattern where the formulations showed higher $\mathrm{r}^{2}$ value for first-order release compared to zero-order. All the formulations showed higher $\mathrm{r}^{2}$ value for Higuchi model compared to Hixon-Crowell and it demonstrates that drug release followed the diffusion mechanism. The release mechanism was further confirmed by release exponent (n) value from Korsemeyer-Peppas model. The 'n' value was found to be greater than 0.6 for all the formulations which indicated that drug release from implants followed non-Fickian diffusion i.e. a combination of both diffusion and erosion mechanism.

\section{Conclusions}

Triamcinolone acetonide was successfully formulated as prolong released ISFI using PLGA and NMP. All the formulations exhibited good syringeabilty and rheological properties. The drug release was constant and sustained over a period of 42 days. Therefore, the developed formulations may improve patient's compliance and convenience by reducing the frequency of drug administration and could be a viable alternative to existing treatments.

\section{Conflict of interest}

All the authors (Ravi Sheshala, Gan Chew Hong, Wong Pui Yee, Venkata Srikanth Meka and Thakur Raghu Raj Singh) declare that they have no conflict of interest. 


\section{References}

1. World Health Organization, Global Data on Visual Impairments 2010, 2012.

2. Rani TR, Mohit S. An insight to ophthalmic in situ gel: an overview. Int Res J Pharm. 2012; 3: 16-21.

3. Thakur RRS. Visual impairmentisepe Blindness: Treatments, Challenges \& Future Developments. UKICRS (United Kingdom \& Ireland Controlled Release Society) symposium, 2013.

4. Kempe S, Mader K. In situ forming implants-an attractive formulation principle for parenteral depot formulations. J Control Release. 2012; 161: 668-79.

5. Bari H. A prolonged release parenteral drug delivery system- an overview. Int J Pharm Sci Rev Res. 2010; 3: 1-11.

6. Thakur RRS, McMillan HL, Jones DS. Solvent induced phase inversion-based in situ forming controlled release drug delivery implants. J Control Release. 2014; 176: 8-23.

7. Dunn RL, English JP, Cowsar DR, Vanderbilt DD. Biodegradable in-situ forming implants and methods of producing the same. United States Patent US5990194 A. 1999.

8. Schoenhammer K, Boisclair J, Schuetz H, Petersen H, Goepferich A. Biocompatibility of an injectable in situ forming depot for peptide delivery. J Pharm Sci. 2010; 99: 4390-9.

9. Madhu M, Shaila L, Anwar BJ. Biodegradable injectable implant systems for sustained delivery using poly (lactide-co-glycolide) copolymers. Int J Pharm Pharm Sci. 2009; 1: 103-7.

10. Ueda H, Hacker MC, Jo HS, Ammon DM, Borazjan RN. Injectable, in situ forming poly(propylene fumarate)-based ocular drug delivery systems, J Biomed Mater Res A. 2007; 83:656-66.

11. Ahmed I. The noncorneal route in ocular drug delivery. In: Mitra AK, editor. Ophthalmic drug delivery systems. New York: Marcel Dekker; 2003. pp. 335-363.

12. Ravivarapu HB, Moyer KL, Dunn RL. Sustained activity and release of leuprolide acetate from an in situ forming polymeric implant. AAPS PharmSciTech. 2000; 1:1-8.

13. Gunda S, Hariharan S, Mandava N, Mitra AK. Barriers in ocular drug delivery. In: Tombran-Tink J, Barnstable CJ, editors. Ophthalmology Research: Ocular Transporters in Ophthalmic Diseases and Drug Delivery. New Jersey: Humana Press; 2008. pp. 399-413.

14. Singh TRR, Fallows SJ, McMillan HL, Donnelly RF, Jones DS. Microneedle-mediated intrascleral delivery of in situ forming thermoresponsive implants for sustained ocular drugdelivery. J Pharm Pharmacol. 2014; 66:584-95.

15. Geroski DH, Edelhauser HF. Drug delivery for posterior segment eye disease. Investig Ophthalmol Vis Sci. 2000; 41:961-4.

16. Falavarjani KG, Nguyen QD. Adverse events and complications associated with intravitrael injection of antiVEGF agents: a review literature. Eye. 2013; 27: 787-94. 